\title{
THERMODYNAMIC BEHAVIOUR OF HYPERSENSITIVE TRANSITION OBSERVED IN SOME THULIUM ION DOPED SYSTEMS
}

\author{
MAHENDRA VYAS ${ }^{*}$, PRAVEEN PUROHIT ${ }^{1}$, GARIMA PRAJAPAT ${ }^{2}$ and H. K. PANDEY ${ }^{3}$ \\ Department of Chemistry, Govt. Engineering College, Bikaner (Raj.) \\ ${ }^{3}$ P. G. Department of Chemistry, Govt. Dungar College, Bikaner (Raj.)
}

\begin{abstract}
The Tm(III) doped systems with various ligands studied with respect to hypersensitive transition The spectroscopic data for hypersensitive transition have been correlated with the thermodynamic parameters. The thermodynamic parameters include thermodynamic efficiency and partition function of the transition.
\end{abstract}

Keywords: Hypersensitive transition,Thulium, N,S,\&O donor ligands.

\section{Introduction}

The intensities of most of the f-f transitions of trivalent lanthanides are little affected by environment of surrounding ions. However, a few transitions are very sensitive to the environment and in the complexed lanthanide ion. They are usually more intense as compared to that of independent lanthanide ion present in the solvent medium. Such transitions are called hypersensitive transitions.

The study of hypersensitive transitions plays an important role in evaluating the effect of ligand environment on $4 \mathrm{f}$ orbital of lanthanide $i^{1-3}$. The recent theories given by Slater-Condon, Lande, Carnall ${ }^{4}$ and Judd-Ofelt ${ }^{5,6}$ about the lanthanide f-f spectra correlate the involvement of $4 \mathrm{f}$-orbitals in terms of the various energy and intensity parameters.

The present paper describes the thermodynamic treatment of hypersensitive transitions of various ligands doped with Tm (III) ion. The transition ${ }^{3} \mathrm{H}_{6}-{ }^{3} \mathrm{H}_{4}$ are said to be hypersensitive in case of Tm (III) ion. The thermodynamic treatment involves the determination of work function and thermodynamic efficiency from the spectroscopic data obtained for the present systems. The thermodynamic parameters resulting from spectroscopic data support the covalency between lanthanide ion and the surrounding ligand.

The present work includes systems of saturated solutions in DMSO involving eight ligands. These include Urea, Thiourea, Dimethyl glyoxime, Semicarbazide, Thiosemicarbazide, Acetaldehyde-Semi-carbazone, N,N-Diphenylthiourea and Diphenyl Glyoxime.

These systems provide saturated ligand environment around Tm (III) ion. The solution spectra have been recorded for the various systems in the visible region 
(400-850 nm). The spectroscopic data (oscillator strengths and energy of transition) have been used to compute thermodynamic parameters. These parameters represent the microscopic behavior of the hypersensitive transition.

\section{Experimental}

By employing doped model, eight systems were prepared (table 1) involving Tm (III) and different ligands. Solution spectra of these systems have been recorded by a standard spectrophotometer in the range 400 to $820 \mathrm{~nm}$.

\section{Calculation of work function and thermodynamic efficiency of the transition}

Thermodynamic parameters may also support covalency (if any in the systems), in metal-ligand interaction in addition to spectral parameters for hypersensitive transitions.

(a) Thermodynamic Efficiency of transition $($ TET $)=\frac{\text { Work function for transition }}{\text { Energy absorbed for transition }}$

By using thermodynamic relation-

$$
\mathrm{A}=\mathrm{E}-\mathrm{TS} \text { and } \mathrm{S}=\mathrm{K} \ln \mathrm{P}_{\mathrm{obs}}
$$

Following relation may be obtained-

$$
\mathrm{A}=\mathrm{E}-\mathrm{KT} \ln \mathrm{P}_{\mathrm{obs}}
$$

Where:-

$A=$ Work function $\left(\mathrm{cm}^{-1}\right)$

$\mathrm{E}=$ Energy absorbed for hypersensitive transition $\left(\mathrm{cm}^{-1}\right)$

$\mathrm{K}=$ Boltzmann constant $=0.6945 \mathrm{~cm}^{-1}$

$\mathrm{T}=$ Absolute temp

$\mathrm{P}_{\mathrm{obs}}=$ Oscillator strength of transition (from eq.1)

$\mathrm{S}=$ Absolute energy.

Thermodynamic efficiency of transition may be expressed as-

$$
T E T=\frac{\text { Work function for transition }(\mathrm{cm})}{\text { Energy absorbed for transition }(\mathrm{cm})}
$$

(b) Calculation of partition function $(\mathrm{Q})$ and ratio of partition function

$$
(\mathrm{Q})=\mathrm{g}_{\mathrm{i}} \mathrm{e}^{-\mathrm{E} / \mathrm{kT}}
$$

Where:

For $\mathrm{Tm}-\mathrm{g}_{\mathrm{i}}=2 \mathrm{~J}+1=9$

(c) Ratio of Partition $\left(r_{p}\right)$

Ratio of Partition $\left(r_{P}\right)=\frac{Q \text { for lanthanide ion system }(\text { doped })}{Q \text { for lanthanide ion }(\text { free ion in solvent })}$ 


\section{Results and Discussion}

The computed values of the thermodynamic parameters (for hypersensitive transition) from the spectroscopic data have been tabulated in Table 1

- The values of work function (A) have been found to be from 12504.69 to 12682.31 .

- The values of TET vary from 1.1884 to 1.1911 .

- The values of partition function $(\mathrm{Q})$ have been found to be from 3.3010 to 7.7425.

- The values of ratio of partition function $\left(r_{p}\right)$ vary from 1.1983 to 2.8106 for Tm (III) doped systems.

The significance of thermodynamic parameters are well understood but their computation from spectroscopic data proposes a microscopic behavior of the $\mathrm{f}-\mathrm{f}$ transition. The present study finds that the microscopic behavior with respect to TET for $\mathrm{Tm}$ (III) doped systems is almost the same but there is a variation in partition function values.

Table 1

VALUES OF THERMODYNAMIC PARAMETERS OF Tm(III) SYSTEMS

\begin{tabular}{|c|c|c|c|c|c|c|c|c|}
\hline $\begin{array}{l}\text { S. } \\
\text { N. }\end{array}$ & $\begin{array}{c}\text { Tm(III) } \\
\text { doped } \\
\text { systems }\end{array}$ & $\begin{array}{c}\text { Energy for } \\
\text { hypersensitive } \\
\text { transition } \\
\left({ }^{3} \mathbf{H}_{4}\right) \\
\left(\mathrm{cm}^{-1}\right)\end{array}$ & $\begin{array}{c}\text { Oscillator } \\
\text { strength for } \\
\text { hypersensitive } \\
\text { transition } \\
\left({ }^{3} \mathbf{H}_{4}\right) \\
\left(\mathrm{X} \mathbf{1 0}^{6}\right)\end{array}$ & $\begin{array}{c}\text { Work } \\
\text { function } \\
\text { (A) } \\
\left(\mathrm{cm}^{-1}\right)\end{array}$ & $\begin{array}{l}\text { Thermo } \\
\text { dynamic } \\
\text { efficiency } \\
\text { of the } \\
\text { transition } \\
\text { (TET) }\end{array}$ & $\begin{array}{c}\text { Partition } \\
\text { function } \\
Q=\mathrm{g}_{\mathrm{i}} \mathrm{e}^{-\mathrm{E} / \mathrm{KT}} \\
\left(\mathbf{X} \mathbf{1 0}^{26}\right)\end{array}$ & $\begin{array}{c}\text { Ratio of } \\
\text { partition } \\
\text { function } \\
\left(\mathbf{r}_{\mathrm{p}}\right)\end{array}$ & $\begin{array}{c}\text { Peacock } \\
\text { relation } \\
\left(\mathbf{K}^{\prime}\right)= \\
\mathbf{P}_{\text {obs }} / \mathrm{vT}_{6}\end{array}$ \\
\hline 1. & $\operatorname{Tm}(\mathrm{III})+\mathrm{L}_{1}$ & 12512.51 & 10.4006 & 14903.05 & 1.1910 & 7.4572 & 2.7070 & 3.7313 \\
\hline 2. & $\operatorname{Tm}(\mathrm{III})+\mathrm{L}_{2}$ & 12512.51 & 10.4006 & 14903.05 & 1.1910 & 7.4572 & 2.7070 & 3.7219 \\
\hline 3. & $\operatorname{Tm}(\mathrm{III})+\mathrm{L}_{3}$ & 12504.69 & 10.4266 & 14894.7 & 1.1911 & 7.7425 & 2.8106 & 5.0057 \\
\hline 4. & $\operatorname{Tm}(\mathrm{III})+\mathrm{L}_{4}$ & 12514.08 & 10.4266 & 14904.09 & 1.1909 & 7.4013 & 2.6867 & 3.7155 \\
\hline 5. & $\operatorname{Tm}(\mathrm{III})+\mathrm{L}_{5}$ & 12515.64 & 10.4266 & 14905.66 & 1.1909 & 7.3459 & 2.6666 & 3.4465 \\
\hline 6. & $\mathrm{Tm}(\mathrm{III})+\mathrm{L}_{6}$ & 12507.82 & 10.4006 & 14898.35 & 1.1911 & 7.6271 & 2.7687 & 3.8004 \\
\hline 7. & $\operatorname{Tm}(\mathrm{III})+\mathrm{L}_{7}$ & 12682.31 & 10.4266 & 15072.32 & 1.1884 & 3.3010 & 1.1983 & 3.2751 \\
\hline 8. & $\mathrm{Tm}(\mathrm{III})+\mathrm{L}_{8}$ & 12507.82 & 10.4006 & 14898.35 & 1.1911 & 7.6271 & 2.7687 & 3.8249 \\
\hline
\end{tabular}

Where:- $\mathrm{K}=0.6945, \mathrm{~T}=300 \mathrm{~K}$

\section{Acknowledgment}

The authors are grateful to Principal, Dungar College, Bikaner for providing necessary facilities. The authors are also highly thankful to Prof. R.S. Yadav, Principal, Govt. Engineering College, Bikaner, Dr. Chanchal Kachhawa, Mr. R.C. Beniwal \& Mr. Gaorav Joshi Govt. Engineering College, Bikaner for their whole hearted full co-operation 


\section{References}

1. S. N. Mishra, S. B. Mehta and K. Venkatsubramaniyam, Asian J. Chem. Rev., 2, 100, (1991).

2. S. H. Maran and C.P. Prutton, Principles of Physical Chemistry, Amerind Publishing Co. Pvt. Ltd., Delhi (1972).

3. S. Maurya, D. Balani and G.K. Joshi, Asian J. Chem., 7, 523 (1995).

4. B. R. Judd. Phy. Rev., 127, 750 (1962).

5. G. S. Ofelt, J. Chem. Phys., 37, 511 (1962).

6. W. T. Carnall, J. Chem. Phys. 42, 3797 (1965). 